\title{
A Tale of Two Systems: Peptide Ligand-Receptor Pairs in Plant Development
}

\author{
J.S. LEE AND K.U. TORII \\ Department of Biology, University of Washington, Seattle, Washington 98195-1800; \\ Howard Hughes Medical Institute, University of Washington, Seattle, Washington 98195-1800 \\ Correspondence: ktorii@u.washington.edu
}

\begin{abstract}
Plants have developed intercellular signaling systems that use secreted peptides and plasma membrane-localized receptorlike kinases (RLKs). Although there has been little experimental evidence linking specific peptide ligands to receptors, recent studies of several ligand-receptor pairs have revealed their increasingly important roles in cell-cell communications during plant development. In this review, we focus on two specific families of plant peptides: the CLAVATA3/ENDOSPERM SURROUNDING REGION (CLE) peptide family and the EPIDERMAL PATTERING FACTOR (EPF) family, along with their corresponding RLKs. We discuss how these two unrelated peptide-mediated signaling systems control plant cell fate and development using similar receptor kinases as well as the mechanisms for how these peptide ligand-receptor pairs precisely regulate various distinct aspects of plant development at the level of ligand-receptor recognition and signal transduction.
\end{abstract}

Multicellular organisms depend on cell-to-cell communication to coordinate both development and environmental responses across diverse cell types. Intercellular signaling is particularly important in plants because development is primarily postembryonic and organs are formed continuously during the life of the plant. Since the identification of systemin, the first plant peptide signal shown to function in the wounding response (Pearce et al. 1991), a number of peptides have subsequently been identified, including phytosulfokine (PSK), growth-promoting factors that also attenuate plant immune responses in Arabidopsis (Matsubayashi and Sakagami 1996; Igarashi et al. 2012); S-locus cysteine-rich protein/S-locus protein 11 (SCR/SP11), male determinants of self-incompatibility response in Brassicaceae (Schopfer et al. 1999); and LUREs, pollen-tube attractants secreted by synergid cells in Torenia (Okuda et al. 2009). These findings demonstrate that, similarly to other eukaryotes, plant cells use secreted peptides as important signaling molecules for cell-cell communication. Perception of these secreted peptides commonly involves plasma membrane-localized receptor-like kinases (RLKs). Among RLKs, leucine-rich repeat (LRR)-RLKs, that contain repeated amino-acid sequences including a large proportion of leucine in the extracellular domain, represent the largest subgroup of RLKs in plants (Shiu and Bleecker 2001; Torii 2004). On binding of peptides at the extracellular LRR domain, the cytoplasmic kinase of an LRRRLK is activated and initiates various downstream cellular responses, resulting in cell growth, proliferation, or differentiation.

The Arabidopsis genome contains more than 1000 genes encoding putative peptides and more than 200 LRR-RLKs. These incredibly large numbers and their identified biological roles imply extreme diversity and complexity of peptide signaling processes as well as their central importance in controlling multiple biological processes in plants (Lease and Walker 2006; Hanada et al. 2007). Thus far, however, only a handful of these putative peptides have experimental evidence to support specific peptide ligand-receptor pairs controlling biological processes in plants.

In this review, we describe two relatively widely studied plant peptide families, CLE and EPF, that have been shown to control various aspects of plant development. We discuss the similarities and differences between these two unrelated peptide-mediated signaling systems, using related RLKs, with the aim of illuminating common themes in peptide control of developmental pathways in plants at the level of ligand perception. Although a similar review has been published before (Katir et al. 2011), we specifically focus on the very latest findings on CLE and EPF signaling to directly compare and contrast the mechanisms of receptor binding, feedback regulations, and signal specificities, rather than describing them separately. For comprehensive, updated reviews of each signaling system, see Betsuyaku et al. (2011a) and Torii (2012).

\section{MOLECULAR CHARACTERISTICS OF CLE AND EPF FAMILY PEPTIDES}

CLE peptides are the largest group of secreted peptides identified in plants. They are named for the CLAVATA3 (CLV3)/ENDOSPERM SURROUNDING REGION (ESR)-related gene family. Of the 32 CLE genes in Arabidopsis, some members have a role in a broad range of developmental processes such as shoot and root meristem development, vascular cell differentiation, and seed development (Wang and Fiers 2010; Fiume and Fletcher 
2012). CLE peptides are small posttranslationally modified peptides with several common molecular characteristics (Matsubayashi 2011). They encode small polypeptides of less than 20 amino acids. These peptides possess a conserved 14-amino-acid CLE domain near the carboxyl terminus (Matsubayashi 2011). Identification of several mature CLE peptides revealed that the CLE domain in some of these peptides is subjected to posttranslational modifications to give biologically active peptides. For example, mature CLV3 peptide, a founding member of the CLE family, was identified as a 12- or 13amino-acid proline-hydroxylated peptide derived from the CLE domain (Matsubayashi 2011). In addition, posttranslational arabinosylation was found to occur on the seventh proline residue of several CLE peptides, including CLV3; this sugar modification strongly enhances its binding to corresponding receptor CLV1 and its biological effect (Ohyama et al. 2009). Interestingly, it was recently reported that application of synthetic CLE18 without any modifications triggers long, wavy roots, a phenotype similar to Arabidopsis plants overexpressing the CLE18 gene (Meng et al. 2012). This suggests that CLE genes generate multiple different forms of mature peptides both without and with posttranslational modifications, and their existence might contribute to expand their diversity for efficient fine-tuning controls of various biological processes in plants.

EPF1, a founding member of the EPF family of peptides, was originally identified through large-scale overexpression screening for novel putative peptides as a negative regulator of stomatal development (Hara et al. 2007). Subsequent bioinformatic approaches identified several EPF1 homologs, all of which code for secreted cysteine-rich peptide (Hara et al. 2009; Hunt and Gray 2009; Sugano et al. 2010; Matsubayashi 2011). There are 11 EPF family members in Arabidopsis and they all have a characteristic, carboxy-terminal domain containing six or eight cysteine residues that are essential for the formation of intramolecular disulfide bonds (Rychel et al. 2010). Recent biochemical and structural studies on EPF-LIKE9 (EPFL9)/Stomagen, a member of the EPF family of peptides, revealed that the mature form of EPFL9 is 45 amino acids, which is relatively large compared with CLE peptides that have three intramolecular disulfide bonds derived from its carboxy-terminal end (Kondo et al. 2010; Ohki et al. 2011). Misfolded and unfolded EPFL9/Stomagen generated via removal of conserved cysteine residues resulted in inactive peptide because of its improper structural conformation. This strongly suggests that correct disulfide formation is critical for EPF family members, including EPFL9, to exhibit proper folding and activity (Ohki et al. 2011).

The nuclear magnetic resonance (NMR) structure of the EPF family peptide EPFL9/Stomagen revealed a conserved peptide backbone composed of an antiparallel $\beta$ sheet supported by three disulfide bonds, which is intercepted by a less conserved loop domain (Ohki et al. 2011). Domain-swap experiments between EPFL9/ Stomagen and EPF2, which are positive and negative regulators of stomatal development, respectively, revealed that the divergent loop domain is likely to determine the functional specificity of each EPF peptide (Ohki et al. 2011). It would be enlightening to investigate further the relationship between structure and biological function by analyzing the loop region and its binding affinity to the receptor among EPF family members known to have different and redundant biological functions.

\section{LRR-CONTAINING RECEPTORS MEDIATE CLE PEPTIDE SIGNALING}

Studies on the maintenance of stem cells in the shoot apical meristem (SAM) had revealed three receptor complexes, CLV1 homomers, CLV2-CORYNE (CRN)/ SOL2 heteromers, and RPK2 homomers, that are likely to act independently of one another (Ogawa et al. 2008; Guo et al. 2010; Kinoshita et al. 2010). Among these, CLV1 and RPK2 encode LRR-RLKs, whereas CLV2 encodes an LRR-RLP lacking a cytoplasmic kinase domain. CLV3 is specifically expressed in the cells of the stem cell niche (Fletcher et al. 1999), but has a non-cell-autonomous effect on the interior meristem cells, where mature CLV3 is perceived by these three receptor complexes to restrict stem cell population within the SAM. clv1 clv2 rpk2 triple mutants show a massively overproliferated SAM, as seen in clv3 single mutants (Kinoshita et al. 2010), and biochemical studies have shown that CLV3 indeed can directly bind to CLV1 and CLV2 (Ogawa et al. 2008; Guo et al. 2010). Other LRR-RLKs, BARELY ANY MERISTEM (BAM) receptors close to CLV1, have also been suggested to regulate SAM homeostasis by promoting stem cell maintenance (DeYoung et al. 2006). Unlike CLV1, they are broadly expressed and control various developmental processes (DeYoung et al. 2006; Hord et al. 2006). BAM can directly bind to CLE9, which has been shown to be specifically expressed in stomatal lineage cells (Shinohara et al. 2012). Thus, it is possible that BAM also has a role in stomatal development.

A similar CLE peptide ligand-receptor pair, CLE41/ CLE44-PXY/TDR, controls another type of stem cell tissue, procambium, which is located in the vascular system (Fisher and Turner 2007; Hirakawa et al. 2008). CLE41 and CLE44 (known as tracheary element differentiation inhibitory factor, TDIF) are expressed in phloem cells, and they non-cell-autonomously suppress the differentiation of adjacent procambial cells into xylem cells and promote their proliferation (Hirakawa et al. 2008; Etchells and Turner 2010). Both forward- and reverse-genetics approaches identified the receptor for CLE41. pxy ( phloem intercalated with xylem) mutant was identified for its disruption of phloem-xylem polarity (Fisher and Turner 2007). Other groups took a targeted approach and screened for procambial-specific LRR-RLKs, whose loss-of-function mutations lead to CLE41/44 insensitivity (Hirakawa et al. 2008). This approach indeed established TDR/PXY as a CLE41/44 receptor in the regulation of vascular stem cells (Hirakawa et al. 2008). The overexpression of CLE41 resulted in pleiotropic phenotypes, including a dwarf appearance with numerous bushy, small leaves, suggesting that CLE41/44 is 
involved in many biological processes other than vascular meristem maintenance (Whitford et al. 2008).

Another interesting CLE peptide named CLE40 requires the ACR4 receptor kinase, in which receptor ectodomain is unrelated to the LRR domain found in other known CLE receptors (Stahl et al. 2009). CLE40 was shown to be expressed in the columella stem cells, and the cle 40 mutant shows multiple layers of columella stem cells, which is similar to the phenotype of the acr4 (Stahl et al. 2009). Consistent with this, acr4 mutants are nearly insensitive to CLE40 peptide application, supporting the view that CLE40 and ACR4 form a ligand-receptor pair in root meristem maintenance (De Smet et al. 2008; Hirakawa et al. 2008). However, direct biochemical interaction between CLE40 and ACR4 remains to be examined and this would provide new insights into the diverse biochemical basis used to perceive CLE peptide using receptor kinases with divergent ectodomain structures.

CLE peptides also have additional biological roles beyond stem cell regulation. CLE8 has recently been identified as a regulator of seed development (Fiume and Fletcher 2012). Here, CLE8 is extensively expressed in early embryos and endosperm and regulates embryo and suspensor proliferation. No LRR-RLK, acting as a CLE receptor in most cases, has been identified to act as a receptor for CLE8 peptide in seed, but it can be speculated that candidates would be those that are preferentially expressed in the developing seed.

\section{ERECTA INVOLVED IN VARIOUS EPF PEPTIDE SIGNALING}

Recent studies in Arabidopsis indicate that LRR-RLKs also mediate EPF signaling. The Arabidopsis ERECTA is an LRR-RLK regulating diverse aspects of plant developmental and physiological processes (van Zanten et al. 2009). It has been known that ERECTA and its two functional paralogs ERL1 and ERL2 have a role in controlling stomatal patterning and differentiation by perceiving the signals from some EPF peptides, such as EPF1 and EPF2. Biochemical and phenotypic studies using mature EPF1 and EPF2 peptides further established EPF2-ERECTA and EPF1-ERL1 as ligand-receptor pairs specifying two steps of stomatal development: initiation and spacing division (Lee et al. 2012). Two other EPF-like peptides, EPFL4 and EPFL6, have redundant functions as ERECTA signals in a different developmental process: inflorescence growth (Uchida et al. 2012a). In vivo studies suggest that EPFL4 and EPFL6 peptides are secreted from the stem endodermis and recognized by ERECTA in phloem cells noncell autonomously to promote cell proliferation for inflorescence elongation. Interestingly, EPFL6/CHALLAH (CHAL) was also isolated as a regional suppressor of too many mouths (tmm), which is a LRR-RLP controlling stomata patterning (Abrash and Bergmann 2010). However, their expression patterns are not consistent with a role in stomatal development and neither epfl6 single nor the epfl4 epfl6 double mutants have a detectable epidermal phenotype (Abrash and Bergmann 2010; Abrash et al. 2011; Uchida et al. 2012a).
Thus, under normal developmental conditions, the main role of EPFL4 and EPFL6 appears to be proper control of inflorescence architecture. Combined, this provides a good example of intertissue layer (i.e. endodermis-phloem) communication via peptide ligand-receptor pair, EPFL4/EPFL6-ERECTA, analogous to phloem-procambial communication via CLE40/41-TDR/PXY (see above).

It has been shown that transfer of clvl alleles into the Ler ecotype harboring the erecta mutation strongly enhanced the clv1 phenotype, indicating an overlap in function between CLV and ERECTA in SAM regulation (Dievart et al. 2003). This observation opens up the possibility that two unrelated peptide families, EPF and CLE, could work together in the same developmental processes either independently or cooperatively using LRR-RLKs. Indeed, recent study demonstrates the specific role of ERECTA-family RLKs in stem-cell homeostasis in the SAM (Uchida et al. 2012b). Similarly to the clv1 mutant, the er erl1 erl2 triple mutant exhibits enlarged SAM. Interestingly, the er erll erl2 SAMs are hypersensitive to cytokinin-induced stem cell proliferation, indicating that the ERECTA family may buffer cytokinin responsiveness within SAM (Uchida et al. 2012b). It would be interesting to address whether any of the remaining EPFL peptides function as a signaling ligand for this buffering action.

\section{FEEDBACK LOOPS CONTROL BOTH CLE- AND EPF-MEDIATED SIGNALING}

Studies of CLE peptides in stem cell regulation highlight the transcription factors of the WUSCHEL (WUS)related homeobox protein family as key signaling downstream CLV3 secreted from the stem cells in the central zone in SAM restricts the expression of the WUS within the organizing center (Schoof et al. 2000). WUS is, in turn, required for $C L V 3$ expression in the stem cell, and this negative feedback loop is key to maintaining the fine balance of stem cell proliferation and differentiation (Fig. 1A). Although there are few differences at the operational level, similar signaling modules regulate stem cell homeostasis in the root and vasculature. CLE40 originates from differentiated root cells and acts through the ACR4 receptor to repress $W O X 5$ expression to the quiescent center. Negative regulation of $W O X 5$ is required for maintaining stem cells by CLE40, resembling the CLV3-WUS feedback loop in SAM except that the CLE40 signal in the root originates from differentiated cells (Stahl et al. 2009). The CLE-WOX feedback regulation in vasculature also exists. Unlike other stem cell regulations by CLE peptides, however, CLE41 secreted by phloem cells upregulates the expression of WOX4 to support stem cell proliferation (Hirakawa et al. 2010). A recent study of CLE8 in seed development further indicates that the CLE-WOX feedback loop is a common regulatory mechanism to control various developmental processes beyond the stem cells (Fiume and Fletcher 2012).

The basic helix-loop-helix (bHLH) transcription factor SPEECHLESS (SPCH) is a positive regulator of 
A
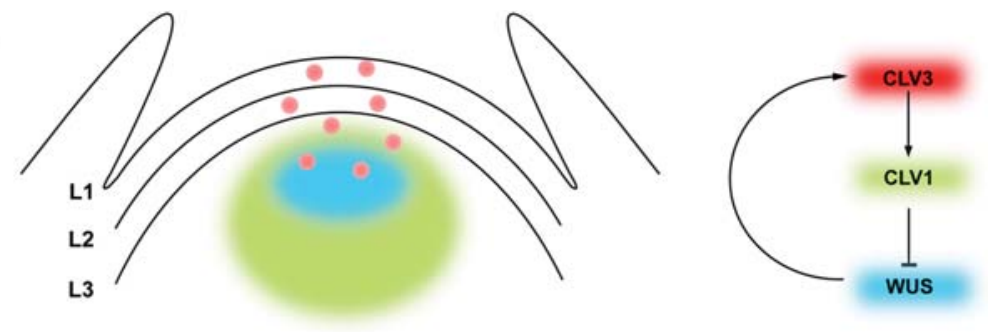

B
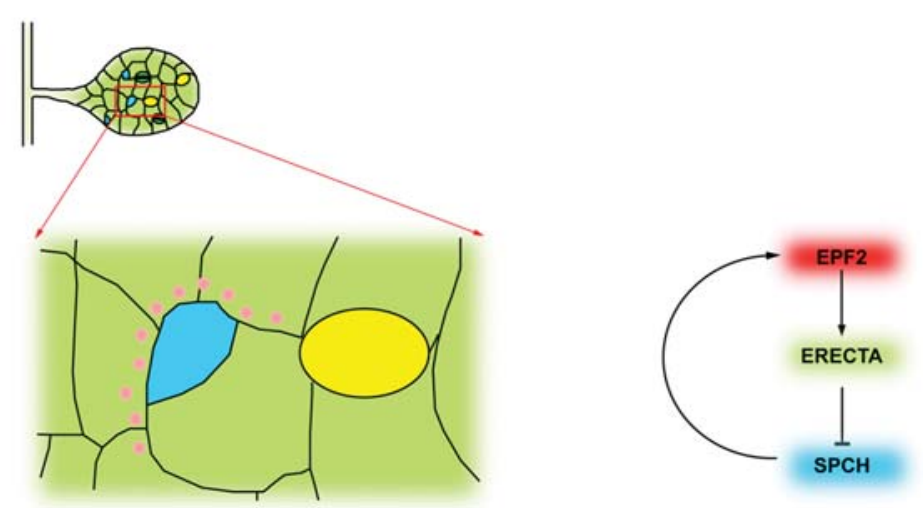

Figure 1. Regulation of stem cell fate in the SAM and meristemoid identity during stomatal patterning. (A) CLV3 (red balls) secreted from the meristematic region of the SAM is perceived by a CLV1 receptor expressed in underlying cells (green) to restrict stem cell development by negatively regulating WUS expression (blue). (B) EPF2 (red balls) secreted from early stomatal lineage cells, where expression of $S P C H$ (blue) is highly accumulated, is perceived by ERECTA receptor on neighboring cells (green) to inhibit stomatal cell fate. Conceptual models of stem cell fate regulation in the SAM (CLV3-CLV1-WUS) and during stomatal development (EPF2ERECTA-SPCH) are on the right. (Arrows) Positive interactions; (barred arrows) repressive interactions.

stomatal lineage initiation. It is expressed in most protodermal cells and later its expression levels in pavement cells are gradually decreased, although its expression is maintained in stomatal lineage cells for these cells to undergo stomatal differentiation (MacAlister et al. 2007; Pillitteri et al. 2007). Interestingly, expression patterns of $E P F 2$, an inhibitor of entry asymmetric division, are overlapped with $S P C H$, and $S P C H$ is required for $E P F 2$ expression (Hara et al. 2009). Along with this, the phenotypes of epf 2 and $E P F 2$ overexpression are nearly identical to $S P C H$ overexpression and spch, respectively (Hara et al. 2009). Thus, it is possible that, similar to CLE signaling in stem cell regulation, a feedback loop exists in EPF signaling to reinforce proper stomatal patterning: $\mathrm{SPCH}$ in protodermal cells induces $E P F 2$, which in turn inhibits surrounding neighboring cells from initiating stomatal lineages (Fig. 1B). The exact molecular mechanism of this EPF2-SPCH feedback loop remains to be clarified and target transcription factors for EPFL4/6-ERECTA module have not been identified.

\section{MAPK CASCADE: A LINK FROM CELL SURFACE RECEPTORS TO TRANSCRIPTION FACTORS}

What are the signaling components connecting CLE and EPF peptide signal-receptor modules to transcription factors? Involvement of mitogen-activated protein kinase (MAPK) cascade, a canonical signal transducer in plants, animals, and fungi (Widmann et al. 1999; Andreasson and Ellis 2010), in CLV and EPF signaling pathways has become evident. Exogenous application of CLV3 peptides stimulates MPK6 activity in wild-type Arabidopsis seedlings (Betsuyaku et al. 2011b). MPK6 activity in $c l v 1$ was higher than that of wild type, indicating that CLV1 negatively regulates the MAPK cascade. Accordingly, conditional overexpression of a dominant-negative form of MKK4, which is a known upstream kinase of MPK6, suppressed the abnormalities of $\mathrm{clv} l$ in the carpel (Betsuyaku et al. 2011b).

During stomatal development, EPF peptide signals received by ERECTA family are also likely to be mediated via a MAPK pathway, containing the MAPKKK YODA (YDA), the MAPKKs MKK4/5, and the MAPKs MPK3/6 for proper stomatal distribution (Bergmann et al. 2004; Wang et al. 2007). Constitutive activation of these MAPK cascade components leads to an epidermis devoid of stomata, and their loss of function overwhelmingly produces stomatal clusters, indicating that this MAPK module negatively regulates stomatal development via inhibition of the activity of the bHLH transcription factor specifying stomatal differentiation (Bergmann et al. 2004; Wang et al. 2007). In vitro phosphorylation of SPCH and the important role of phosphorylation-dependent SPCH degradation by MPK3/6 have indeed been demonstrated (Lampard et al. 2008).

How can the same MAPK components, such as MKK4/5 and MPK3/6, modulate both CLE- and EPF- 
mediated signaling involved in discrete developmental processes? In animals, signaling specificity of MAPK cascades results from the formation of multiprotein complexes, at the core of which is often a scaffold protein (Tanoue and Nishida 2003). Thus, scaffold proteins specific for CLE and EPF signaling may exist and they have a major impact on discrete developmental outcomes using a common MAPK module. Alternatively, availability of substrate in specific developmental processes may be a key factor contributing to signaling specificity of CLE and EPF peptides.

\section{FACTORS THAT DETERMINE THE SPECIFICITY OF CLE AND EPF SIGNALING PATHWAYS}

The unrelated CLE and EPF signals transmitted to induce specific biological response use similar receptor kinases, LRR-RLKs. It is not clear how activation of a receptor by a specific ligand could use the currently known intracellular signaling pathways to transduce a unique biological response, but it is evident that the availability and distribution of peptide signals for corresponding receptors may in part account for the specificity.

In vitro experiments using synthetic CLE peptides showed that the phenotype of clv3 in the SAM could be restored with the use of several different CLE peptides, indicating that receptors are able to recognize a certain degree of CLE sequence variants (Kinoshita et al. 2007). Only a handful of CLE peptides in Arabidopsis have been assigned a clear function to date and there is no evidence that the redundancy actually occurs in planta. Therefore, high and specific expression of each CLE peptide, which is not able to diffuse far, along with its cognate receptor would be important for their endogenous functional specificity. Indeed, Arabidopsis CLE genes are expressed in varieties of cell types and organs (Jun et al. 2010).

It has been shown that ERECTA-family LRR-RLKs mediate activity of at least four EPF family members, EPF1, EPF2, EPFL4, and EPFL6/CHAL, implying that multiple EPF peptides with distinct biological functions possess the capacity to activate the same receptors, ERECTA-family LRR-RLKs. Although the interaction between EPFL9/Stomagen and ERECTA-family kinases has not yet been tested, genetic evidence also suggests that EPFL9/Stomagen (a positive regulator) might compete in binding for the same receptors with EPF2 (a negative regulator) during stomatal development (Sugano et al. 2010). It is thus possible that different tissue distribution of each EPF gene expression is also an important factor in determining the specificity of EPF function through broadly expressed ERECTA-family receptors. Along with this, it has been shown that EPF1 and EPF2 are expressed in different stages of stomatal lineage cells, but EPFL4 and EPFL6 are expressed in internal tissue (endodermis) of developing inflorescence stems instead, supporting their biological role in controlling a specific developmental process, inflorescence growth (Abrash et al. 2011; Uchida et al. 2012a).
Are there any other factors that contribute signaling specificity at the level of ligand-receptor recognition? ERECTA-family receptors bind to both EPF1 and EPF2 in vitro, but they exhibit specificity in vivo during stomatal development: EPF2-ERECTA pair for initiation and EPF1-ERL1 pair for spacing division steps (Lee et al. 2012). Although different expression patterns of these EPFs and their corresponding main receptors during stomatal development may contribute to in vivo specificity in part, it is possible that each EPF signal recruits specific signaling components in vivo to form multireceptor protein complexes to regulate different developmental processes. For instance, the composition of receptor complexes during stomatal development is likely to be affected and/or activated in response to each EPF signal: ERECTA homomer for EPF2 and ERL1 homomer for EPF1 signal. TMM has been shown to interact directly with ERECTA-family receptors. Therefore, in this context, TMM would be one of the factors modulating ERECTA-family signaling specificity depending on the availability of each EPF and different cell types (Lee et al. 2012).

Unlike the EPF signaling, CLV3 signaling is mediated by the three major receptor complexes, CLV1 homomer, CLV2-CRN heteromer, and RPK2 homomer, in parallel, indicating that these receptor complexes independently bind to the CLV3 signal in vivo and activate the intracellular signaling pathway for SAM homeostasis (Bleckmann et al. 2010; Zhu et al. 2010). Interestingly, a recent study showed that CLV3 reduces the amount of plasma membrane-localized CLV1 by inducing CLV1 protein trafficking to lytic vacuoles (Nimchuk et al. 2011). This could be the mechanism not only for signal attenuation but also for signal specificity, by allowing the receptor to be exposed to specific downstream targets that were inaccessible at the plasma membrane upon a particular ligand signal.

\section{CONCLUSIONS AND PERSPECTIVES}

Exciting progress regarding cell-cell communication via secreted peptides in plants has been made in recent years. As described above, a number of studies on two unrelated plant peptides, CLE and EPF, have revealed a striking similarity. Both peptides use similar downstream signaling components, consisting of the LRR-RLKs, MAPK cascades, and transcription factors (WOX TFs for CLE peptides and bHLH TFs for EPF peptides) to regulate various meristemic activities in plants. The recent identification of the potential EPF2-SPCH negative feedback regulation that balances proliferation and differentiation in stomatal development reveals further molecular parallels between CLE and EPF signaling (Fig. 1). It has become increasingly evident that both CLE and EPF peptides are involved in various aspects of plant development other than meristem maintenance. The identification of CLE function in plant-microbe interactions (Wang et al. 2001, 2005) further provides new insights into CLE signaling and encourages the consideration of 
CLE peptide as ligands in many other pathways. It would be interesting to explore whether any other plant pathogens also contain similar ways to mimic EPF peptide signals in the host as a mechanism for plant parasitism.

One of the important future challenges is to understand how these two different classes of peptides elicit unique biological responses using the same sets of receptors, LRR-RLKs. The existence of many CLE/EPF peptides and LRR-RLKs might contribute to the fine-tuning controls of specific biological processes in various plant tissues. In addition, it is possible that signals from many different CLE and EPF peptides are perceived by the same set of receptors that have specific functions either by recruiting a unique set of signaling proteins or using differential combinations of the preexisting pool of receptors. Imaging of the spatial distribution of peptides and the corresponding receptors combined with proteomic approaches should advance our understanding of how plant cells process specific information at the level of ligand-receptor recognition in the future.

\section{ACKNOWLEDGMENTS}

We thank Drs. Bob Kao and Christine Shyu for comments. The authors' work was supported by the National Science Foundation grants IOS-0520548 and IOS0744892 and the JST PRESTO (Precursory Research for Embryonic Science and Technology) award to K.U.T. J.S.L. was a recipient of the Canadian NSERC (National Science and Engineering Research Council) postdoctoral fellowship, and K.U.T. is an investigator of the Howard Hughes Medical Institute-Gordon and Betty Moore Foundation.

\section{REFERENCES}

Abrash EB, Bergmann DC. 2010. Regional specification of stomatal production by the putative ligand CHALLAH. Development 137: 447-455.

Abrash EB, Davies KA, Bergmann DC. 2011. Generation of signaling specificity in Arabidopsis by spatially restricted buffering of ligand-receptor interactions. Plant Cell 23: 2864-2879.

Andreasson E, Ellis B. 2010. Convergence and specificity in the Arabidopsis MAPK nexus. Trends Plant Sci 15: 106-113.

Bergmann DC, Lukowitz W, Somerville CR. 2004. Stomatal development and pattern controlled by a MAPKK kinase. Science 304: 1494-1497.

Betsuyaku S, Sawa S, Yamada M. 2011a. The function of the CLE peptides in plant development and plant-microbe interactions. Arabidopsis Book 9: e0149.

Betsuyaku S, Takahashi F, Kinoshita A, Miwa H, Shinozaki K, Fukuda H, Sawa S. 2011b. Mitogen-activated protein kinase regulated by the CLAVATA receptors contributes to shoot apical meristem homeostasis. Plant Cell Physiol 52: 14-29.

Bleckmann A, Weidtkamp-Peters S, Seidel CA, Simon R. 2010. Stem cell signaling in Arabidopsis requires CRN to localize CLV2 to the plasma membrane. Plant Physiol 152: 166-176.

De Smet I, Vassileva V, De Rybel B, Levesque MP, Grunewald W, Van Damme D, Van Noorden G, Naudts M, Van Isterdael G, De Clercq R, et al. 2008. Receptor-like kinase ACR4 restricts formative cell divisions in the Arabidopsis root. Science 322: 594-597.

DeYoung BJ, Bickle KL, Schrage KJ, Muskett P, Patel K, Clark SE. 2006. The CLAVATA1-related BAM1, BAM2 and
BAM3 receptor kinase-like proteins are required for meristem function in Arabidopsis. Plant J 45: 1-16.

Dievart A, Dalal M, Tax FE, Lacey AD, Huttly A, Li J, Clark SE. 2003. CLAVATA1 dominant-negative alleles reveal functional overlap between multiple receptor kinases that regulate meristem and organ development. Plant Cell 15: 1198-1211.

Etchells JP, Turner SR. 2010. The PXY-CLE41 receptor ligand pair defines a multifunctional pathway that controls the rate and orientation of vascular cell division. Development 137: 767-774.

Fisher K, Turner S. 2007. PXY, a receptor-like kinase essential for maintaining polarity during plant vascular-tissue development. Curr Biol 17: 1061-1066.

Fiume E, Fletcher JC. 2012. Regulation of Arabidopsis embryo and endosperm development by the polypeptide signaling molecule CLE8. Plant Cell 24: 1000-1012.

Fletcher JC, Brand U, Running MP, Simon R, Meyerowitz EM. 1999. Signaling of cell fate decisions by CLAVATA3 in Arabidopsis shoot meristems. Science 283: 1911-1914.

Guo Y, Han L, Hymes M, Denver R, Clark SE. 2010. CLAVATA2 forms a distinct CLE-binding receptor complex regulating Arabidopsis stem cell specification. Plant J 63: 889900.

Hanada K, Zhang X, Borevitz JO, Li WH, Shiu SH. 2007. A large number of novel coding small open reading frames in the intergenic regions of the Arabidopsis thaliana genome are transcribed and/or under purifying selection. Genome Res 17: $632-640$.

Hara K, Kajita R, Torii KU, Bergmann DC, Kakimoto T. 2007. The secretory peptide gene EPF1 enforces the stomatal onecell-spacing rule. Genes Dev 21: 1720-1725.

Hara K, Yokoo T, Kajita R, Onishi T, Yahata S, Peterson KM, Torii KU, Kakimoto T. 2009. Epidermal cell density is autoregulated via a secretory peptide, EPIDERMAL PATTERNING FACTOR 2 in Arabidopsis leaves. Plant Cell Physiol 50: 1019-1031.

Hirakawa Y, Shinohara H, Kondo Y, Inoue A, Nakanomyo I, Ogawa M, Sawa S, Ohashi-Ito K, Matsubayashi Y, Fukuda H. 2008. Non-cell-autonomous control of vascular stem cell fate by a CLE peptide/receptor system. Proc Natl Acad Sci 105: $15208-15213$.

Hirakawa Y, Kondo Y, Fukuda H. 2010. TDIF peptide signaling regulates vascular stem cell proliferation via the WOX4 homeobox gene in Arabidopsis. Plant Cell 22: 2618-2629.

Hord CL, Chen C, Deyoung BJ, Clark SE, Ma H. 2006. The BAM1/BAM2 receptor-like kinases are important regulators of Arabidopsis early anther development. Plant Cell 18: 1667-1680.

Hunt L, Gray JE. 2009. The signaling peptide EPF2 controls asymmetric cell divisions during stomatal development. Curr Biol 19: 864-869.

Igarashi D, Tsuda K, Katagiri F. 2012. The peptide growth factor, phytosulfokine, attenuates pattern-triggered immunity. Plant J 71: 194-240.

Jun J, Fiume E, Roeder AH, Meng L, Sharma VK, Osmont KS, Baker C, Ha CM, Meyerowitz EM, Feldman LJ, et al. 2010. Comprehensive analysis of CLE polypeptide signaling gene expression and overexpression activity in Arabidopsis. Plant Physiol 154: 1721-1736.

Katir L, Davies KA, Bergmann DC, Laux T. 2011. Peptide signaling in plant development. Curr Biol 21: R356-R364.

Kinoshita A, Nakamura Y, Sasaki E, Kyozuka J, Fukuda H, Sawa S. 2007. Gain-of-function phenotypes of chemically synthetic CLAVATA3/ESR-related (CLE) peptides in Arabidopsis thaliana and Oryza sativa. Plant Cell Physiol 48: $1821-1825$.

Kinoshita A, Betsuyaku S, Osakabe Y, Mizuno S, Nagawa S, Stahl Y, Simon R, Yamaguchi-Shinozaki K, Fukuda H, Sawa S. 2010. RPK2 is an essential receptor-like kinase that transmits the CLV3 signal in Arabidopsis. Development 137: 3911-3920.

Kondo T, Kajita R, Miyazaki A, Hokoyama M, NakamuraMiura T, Mizuno S, Masuda Y, Irie K, Tanaka Y, Takada S, 
et al. 2010. Stomatal density is controlled by a mesophyllderived signaling molecule. Plant Cell Physiol 51: 1-8.

Lampard GR, Macalister CA, Bergmann DC. 2008. Arabidopsis stomatal initiation is controlled by MAPK-mediated regulation of the bHLH SPEECHLESS. Science 322: 1113-1116.

Lease KA, Walker JC. 2006. The Arabidopsis unannotated secreted peptide database, a resource for plant peptidomics. Plant Physiol 142: 831-838.

Lee JS, Kuroha T, Hnilova M, Khatayevich D, Kanaoka MM, McAbee JM, Sarikaya M, Tamerler C, Torii KU. 2012. Direct interaction of ligand-receptor pairs specifying stomatal patterning. Genes Dev 26: 126-136.

MacAlister CA, Ohashi-Ito K, Bergmann DC. 2007. Transcription factor control of asymmetric cell divisions that establish the stomatal lineage. Nature 445: 537-540.

Matsubayashi Y. 2011. Post-translational modifications in secreted peptide hormones in plants. Plant Cell Physiol 52: $5-13$.

Matsubayashi Y, Sakagami Y. 1996. Phytosulfokine, sulfated peptides that induce the proliferation of single mesophyll cells of Asparagus officinalis L. Proc Natl Acad Sci 93: $7623-$ 7627.

Meng L, Buchanan BB, Feldman LJ, Luan S. 2012. CLE-like (CLEL) peptides control the pattern of root growth and lateral root development in Arabidopsis. Proc Natl Acad Sci 109: 1760-1765.

Nimchuk ZL, Tarr PT, Ohno C, Qu X, Meyerowitz EM. 2011. Plant stem cell signaling involves ligand-dependent trafficking of the CLAVATA1 receptor kinase. Curr Biol 21: $345-$ 352.

Ogawa M, Shinohara H, Sakagami Y, Matsubayashi Y. 2008. Arabidopsis CLV3 peptide directly binds CLV1 ectodomain. Science 319: 294.

Ohki S, Takeuchi M, Mori M. 2011. The NMR structure of stomagen reveals the basis of stomatal density regulation by plant peptide hormones. Nat Commun 2: 512.

Ohyama K, Shinohara H, Ogawa-Ohnishi M, Matsubayashi Y. 2009. A glycopeptide regulating stem cell fate in Arabidopsis thaliana. Nat Chem Biol 5: 578-580.

Okuda S, Tsutsui H, Shiina K, Sprunck S, Takeuchi H, Yui R, Kasahara RD, Hamamura Y, Mizukami A, Susaki D, et al. 2009. Defensin-like polypeptide LUREs are pollen tube attractants secreted from synergid cells. Nature 458: 357-361.

Pearce G, Strydom D, Johnson S, Ryan CA. 1991. A polypeptide from tomato leaves induces wound-inducible proteinase inhibitor proteins. Science 253: 895-897.

Pillitteri LJ, Sloan DB, Bogenschutz NL, Torii KU. 2007. Termination of asymmetric cell division and differentiation of stomata. Nature 445: 501-505.

Rychel AL, Peterson KM, Torii KU. 2010. Plant twitter: Ligands under 140 amino acids enforcing stomatal patterning. J Plant Res 123: 275-280.

Schoof H, Lenhard M, Haecker A, Mayer KF, Jurgens G, Laux T. 2000. The stem cell population of Arabidopsis shoot meristems in maintained by a regulatory loop between the CLAVATA and WUSCHEL genes. Cell 100: 635-644.

Schopfer CR, Nasrallah ME, Nasrallah JB. 1999. The male determinant of self-incompatibility in Brassica. Science 286: $1697-1700$.
Shinohara H, Moriyama Y, Ohyama K, Matsubayashi Y. 2012. Biochemical mapping of a ligand-binding domain within Arabidopsis BAM1 reveals diversified ligand recognition mechanisms of plant LRR-RKs. Plant J 70: 845-854.

Shiu SH, Bleecker AB. 2001. Plant receptor-like kinase gene family: Diversity, function, and signaling. Sci STKE 2001: pre22.

Stahl Y, Wink RH, Ingram GC, Simon R. 2009. A signaling module controlling the stem cell niche in Arabidopsis root meristems. Curr Biol 19: 909-914.

Sugano SS, Shimada T, Imai Y, Okawa K, Tamai A, Mori M, Hara-Nishimura I. 2010. Stomagen positively regulates stomatal density in Arabidopsis. Nature 463: 241-244.

Tanoue T, Nishida E. 2003. Molecular recognitions in the MAP kinase cascades. Cell Signal 15: 455-462.

Torii KU. 2004. Leucine-rich repeat receptor kinases in plants: Structure, function, and signal transduction pathways. Int Rev Cytol 234: 1-46.

Torii KU. 2012. Mix-and-match: Ligand-receptor pairs in stomatal development and beyond. Trends Plant Sci. doi:10.1016/j.bbr.2011.03.031.

Uchida N, Lee JS, Horst RJ, Lai HH, Kajita R, Kakimoto T, Tasaka M, Torii KU. 2012a. Regulation of inflorescence architecture by intertissue layer ligand-receptor communication between endodermis and phloem. Proc Natl Acad Sci 109: 6337-6342.

Uchida N, Shimada M, Tasaka M. 2012b. ERECTA-family receptor kinases regulate stem-cell homeostasis via buffering its cytokinin responsiveness in the shoot apical meristem. Plant Cell Physiol 109: 6337-6342.

van Zanten M, Snoek LB, Proveniers MC, Peeters AJ. 2009. The many functions of ERECTA. Trends Plant Sci 14: 214-218.

Wang G, Fiers M. 2010. CLE peptide signaling during plant development. Protoplasma 240: 33-43.

Wang X, Allen R, Ding X, Goellner M, Maier T, de Boer JM, Baum TJ, Hussey RS, Davis EL. 2001. Signal peptide-selection of cDNA cloned directly from the esophageal gland cells of the soybean cyst nematode Heterodera glycines. Mol Plant Microbe Interact 14: 536-544.

Wang X, Mitchum MG, Gao B, Li C, Diab H, Baum TJ, Hussey RS, Davis EL. 2005. A parasitism gene from a plant-parasitic nematode with function similar to CLAVATA3/ESR (CLE) of Arabidopsis thaliana. Mol Plant Pathol 6: 187191.

Wang H, Ngwenyama N, Liu Y, Walker JC, Zhang S. 2007. Stomatal development and patterning are regulated by environmentally responsive mitogen-activated protein kinases in Arabidopsis. Plant Cell 19: 63-73.

Whitford R, Fernandez A, De Groodt R, Ortega E, Hilson P. 2008. Plant CLE peptides from two distinct functional classes synergistically induce division of vascular cells. Proc Natl Acad Sci 105: 18625-18630.

Widmann C, Gibson S, Jarpe MB, Johnson GL. 1999. Mitogenactivated protein kinase: Conservation of a three-kinase module from yeast to human. Physiol Rev 79: 143-180.

Zhu Y, Wang Y, Li R, Song X, Wang Q, Huang S, Jin JB, Liu CM, Lin J. 2010. Analysis of interactions among the CLAVATA3 receptors reveals a direct interaction between CLAVATA2 and CORYNE in Arabidopsis. Plant J 61: 223-233. 


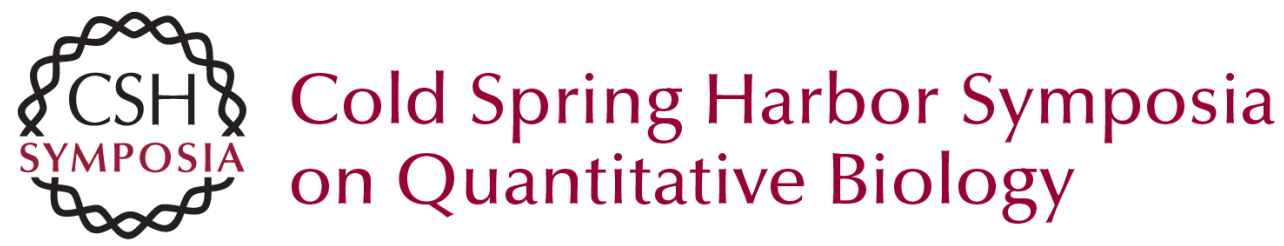

\section{A Tale of Two Systems: Peptide Ligand-Receptor Pairs in Plant Development}

J.S. Lee and K.U. Torii

Cold Spring Harb Symp Quant Biol 2012 77: 83-89 originally published online December 28, 2012

Access the most recent version at doi:10.1101/sqb.2012.77.014886

References This article cites 62 articles, 27 of which can be accessed free at: http://symposium.cshlp.org/content/77/83.full.html\#ref-list-1

\section{License}

Email Alerting Receive free email alerts when new articles cite this article - sign up in Service the box at the top right corner of the article or click here. 